\title{
INSTALACIÓN DE MORISCOS EN ANATOLIA (documento Temimi, de 1613) ${ }^{1}$
}

\author{
Mikel de Epalza*
}

EI profesor Abdeljelil Temimi presentó en el congreso internacional sobre la expulsión de los moriscos, de Sant Carles de la Ràpita, en 1990, un documento de los archivos turcos de Istanbul, de 1613, que mencionaba la instalación de moriscos expulsados de España en cinco ciudades y sus respectivas regiones, en la parte oriental de Anatolia (actualmente sureste y noreste de Turquía y norte de Siria). Ha publicado este documento excepcional repetidas veces, en España y en Túnez, con su correspondiente estudio y con traducciones al árabe y al francés ${ }^{2}$.

* Catedrático de Estudios Árabes e Islámicos. Universidad de Alicante.

1. Seguimos un sistema de transcripción simplificado de las palabras árabes y turcas. Cuando haya que hacer una trasliteración de un texto, se pondrá en bastardilla y según el sistema de la Encyclopédie de l''islam, sin puntos diacríticos. Ver mapa al final del artículo.

2. Ver A. TEMINI, «Politique Ottomane face à l'implantation et à l'insertion des Morisques en Anatolie», L'expulsió dels moriscos. Consequiències en el món islàmic i en el món cristià. Congrés Internacional 380 aniversari de l'expulsió dels moriscos (M. de EPALZA, edit.), Generalitat de Catalunya, Departament de Cultura, Barcelona, 1994, pp. 164-170; id., Revue d'Histoire Maghrébine, Zaghouan (Tunisia), 61-62, 1991, pp. 143-151; id., Études d'Histoire Morisque, CEROMDI, Zaghouan, 1993, pp. 9-24 (parte en francés) y 7-24 (parte en árabe). Hay que tener en cuenta que el prof. Temimi redactó su traducción y su estudio primero en árabe y luego en francés, lo que es importante para ciertos detalles, como se verá.

El documento en cuestión es un firmán o decreto imperial del sultán otomano, conservado en los archivos centrales de Istanbul. Había sido descubierto y ofrecido al profesor tunecino en 1989 por el investigador argelino Chekib Benafri, autor de una tesis doctoral, defendida en el Departamento de Historia Moderna de la Universidad Complutense de Madrid, en mayo de 1993, a quien Temimi agradece con toda cordialidad.

El Dr. Abdeljelil Temimi es profesor de Historia Moderna de la Universidad de Túnez. y, desde 1982, presidente del Comité Internacional de Estudios Moriscos. Ha sido un promotor muy importante de estudios sobre los moriscos, en las dos últimas décadas, como investigador otomanista y como organizador de encuentros regulares (congresos y simposios) sobre temas moriscos, que publica en su revista Revue d'Histoire Maghrébine y en otras colecciones del centro que ha fundado y dirige en Zaghouan, cerca de Túnez (CEROMDI, Centre d'Études et de Recherches, Ottomanes, Morisques, de Documentation et d'Information). Ver presentación de los primeros años de sus actividades en este campo en M. de EPALZA, "Congresos y publicaciones de Historia árabe en época otomana (Túnez)», Awrâq, Madrid, IX, 1988, pp. 217-221. 
Se ha elaborado esta nota o estudio partiendo de esa edición fotográfica del documento, de su transcripción en turco, de sus traducciones al árabe y al francés y de su presentación y estudio, realizados por Abdeljelil Temimi. Se pretende con ello precisar algo más la identificación de esas cinco ciudades, identificación que no ha realizado Temimi directamente, sino que agradece - en nota 3 del trabajo- al profesor turco Halil Sahilloglu, que se limitó a identificar los nombres. Del estudio y localización de esas cinco ciudades se puede, además, profundizar mucho más en la forma de implantación de los moriscos expulsados de España, tanto en el conjunto del Imperio Otomano turco del XVI-XVII (desde Argelia y los Balcanes hasta Oriente Medio anatólico y árabe en general) como en el imperio cherifiano de Marruecos. También se intenta dilucidar algo más la personalidad del morisco o andalusí Alí Ibn-Muhámmad El Mutafárrique a quien el sultán Ahmad I encarga la organización de esas implantaciones moriscas (Temimi transcribe el nombre El Mutafarrika). En ambos puntos - el geográfico y el personal- este excepcional documento amplía y confirma importantes aspectos de la instalación de los musulmanes expulsados de España, en el mundo islámico, tanto a lo largo del siglo XVI como cuando la gran expulsión de 1609-1614³.

\section{TEXTO SOBRE LAS CIUDADES Y SOBRE EL JEFE MORISCO, EN ANATOLIA}

He aquí el pasaje del firmán imperial otomano, relacionado con la instalación de los moriscos en Anatolia y con su jefe Alí Ibn-Muhámmad El Mutafárrique. La presentación general del texto y de su contexto ha sido realizada por Temimi y será completada en las páginas siguientes ${ }^{4}$. Aquí se presenta la traducción directa del texto francés, antes de corregirla con nuevas lecturas, cotejándola de nuevo con el original turco:

"En nombre de la fraternidad religiosa e islámica, hemos ofrecido ayuda y cuidado a la comunidad morisca, cuando llegó a nuestros reinos bien protegidos de nuestro Imperio, pidiéndonos un lugar para su instalación, para que vivan cultivan-

3. Ver estudio pionero de J.D. LATHAM, «Toward a study of Andalusian immigrations and its place in Tunisian History», Les Cahiers de Tunisie, Túnez, 5, 1957, pp. 203-253 [reeditado y traducido al francés], recolecciones de trabajos en M. de EPALZA y R. PETrT (edits.), Receuil d'études sur les Moriscos Andalous en Tunisie, Madrid, 1974, y en S.M. ZBISs, A.-H. GAFsI, M. Benali y M. de Epalza (edits.), Études sur les Morisques Andalous, Túnez, 1983; el ya mencionado congreso de Sant Carles de la Ràpita; y las síntesis recientes de M. RAZuQ, AlAndalusiyyûn wa-hidjratu-hum ilà al-Magrib khilâla al-qarnayn 16-17, Casablanca, 1988, y M. de Epalza, Los moriscos antes y después de la expulsión, Madrid, 1992 y 1994, y «Estructuras de acogida de los moriscos emigrantes de España en el Mágreb (siglos XIII al XVIII) », Altenativas. Cuadernos de trabajo social, Alicante, 4, 1996, pp. 35-58.

4. Ver bibliografía, nota 1. La traducción francesa se encuentra en el volumen L'expulsió..., p. 169. 
do la tierra; les hemos permitido instalarse en los alrededores de Adana, Azir, Sis, Tarsus y Kars...

...He encargado a uno de ellos, el respetable Ali Bin Mohámed, el Mutafárrika, que Dios le honre y le glorifique, que cuide de sus asuntos y de su seguridad como Emir Sanjak, concediéndole nuestro firmán imperial".

La primera precisión que hay que hacer a la traducción es que la mención traducida por "comunidad morisca" figura en el original turco con las palabras tấifa ("comunidad étnico-religiosa, grupo autónomo reconocido") y mudadjijan ("mudéjares, domesticados, sometidos") 5 . Otras cuatro veces aparece la palabra tâ'ifa (en turco "taifeh", el español "taifa"), refiriéndose a la comunidad de moriscos -sea en Anatolia, sea en 'Tunisia-, sin la precisión de "mudéjar". El significado político del término "taifeh" en la estructuración del Estado otomano se estudiará más adelante.

La primera frase de ese texto tiene además una mención a España (transcrito por Temimi en su forma arabizada moderna Isbâniyâ, pero que es Isbâniyeh en el turco del documento), que no ha sido traducida: "...cuando llegó [de las provincias de España] a nuestros reinos bien protegidos de nuestro Imperio...". Dos veces más aparecerá en el texto el origen de los moriscos: "de las provincias de España" (wilâyet Isbâniyeh), que es quizás traducción turca despreciativa de "los reinos de España", paralela a la que el texto utiliza para definir los propios "reinos [mamâlik] de nuestro Imperio" otomano. Pero el término turco "wilayet" significa simplemente "provincia, país o región organizada políticamente" 6 .

Las precisiones conceptuales y filológicas permiten recuperar algunas informaciones del documento de 1613, perdidas en el itinerario de la traducción del turco al árabe, del árabe al francés y de éste al castellano. Es el método que se va a emplear en todo el conjunto de este trabajo.

\section{IDENTIFICACIÓN DE LAS CIUDADES EN SU CONTEXTO GEOPOLÍTICO}

Las cinco ciudades, a cuyos alrededores se instalan los moriscos expulsados de España, a tenor de ese documento de 1613, serían:

5. La palabra "morisco", clásica en el español del siglo XVI, es evidentemente un término hispano, término técnico de historiadores modernos, que sólo especialistas árabes o turcos emplean, entre ellos Temimi. En cambio el tradicional término árabe "mudéjar" es poco empleado por Temimi y otros historiadores árabes actuales (con la notable excepción de Muhámmad Abdállah Enan, que en cambio titula su libro sobre "moriscos", pionero en árabe, "de los arabes cristianizados" (al-'arab al-mutanassirin) (El Cairo, 1958)).

6. Ver estudios minuciosos en volúmenes de congresos organizados por A. TEMimi: Les provinces arabes et leurs sources documentaires à l'époque ottomane, Túnez, 1984; La vie économique des provinces arabes et leurs sources documentaires à l'époque ottomane, Zaghouan, 1986; La vie sociale des provinces arabes à l'époque ottomane, Zaghouan, 1988. 
1. Adana, importante ciudad, a $50 \mathrm{~km}$ del mar, capital central de la región de Cilicia, llanura costera al sur de las estribaciones orientales de la cordillera del Taurus, desembocadura y deltas de los ríos anatólicos de Seihán (que atraviesa la ciudad) y Ceyhán. Su identificación no presenta ninguna dificultad para Temimi, ni hay razón para ponerlo en duda?.

2. Azir, de la que Sahilloglu, consultado por Temimi, dice vagamente, según el texto francés publicado, traducido al español, que "la región costera que bordea el Golfo de Iskandaroun, del norte al sur, y fue habitada por tribus turcas bajo el nombre de Uzur, transformada en el siglo XVI en Azir" 8 . El texto turco dice claramente 'azîr (sin marcar la primera vocal: Azîr, Uzîr...). El hecho de que no esté identificable ni localizable esa población, que sería seguramente importante -como lo son las otras cuatro de la lista- nos hace proponer la hipótesis de que se trate de la ciudad-fortaleza de `Azâz, de grafía algo semejante y situada también en la región de Iskenderun (Alejandreta), en el paso que da acceso por el norte a la importantísima ciudad de Alepo, actualmente ciudad fronteriza en el norte de Siria, con ruinas de fortaleza 9 .

3. Sis, actualmente llamada Kozan, al noreste de la llanura de Cilicia, en el límite entre la planicie costera del delta del río Ceihán y un paso montañoso de la vecina cordillera del Taurus. Es capital oriental de la región. Su identificación no ha supuesto ninguna dificultad.

4. Tarûslûs (que Temimi corrige oportunamente por Tarsîs, Tarsus actual, patria de Saulo de Tarso, el San Pablo de tanta importancia para el cristianismo primitivo), capital occidental de la Cilicia, también en situación estratégica entre la llanura costera de Cilicia y su límite montañoso occidental.

5. Kars (en el documento Qârs), que Temimi identifica razonablemente con la ciudad conquistada por los turcos en 1534 y convertida en cabeza regional en 1580, tras las primeras luchas entre turcos otomanos y persas safawíes ${ }^{10}$. Pero él cree que esta ciudad está también en la región de Cilicia o golfo de Iskenderun, cuando en realidad está en el noreste de la actual Turquía, en los valles del Cáucaso armenio, al sur de Georgia y en uno de los itinerarios anatólicos más importantes que unen por Erzerum el Mar Negro turco con las altiplanicies iraníes, zona estratégica de todos los conflictos otomano-safawíes de la época.

\footnotetext{
7. Ver L'expulsió..., p. 167.

8. L.C.

9. Agradezco a Marisa Soler, bibliotecaria del Instituto de Geografía de la Universidad de Alicante, su preciosa ayuda para obtener mapas de esa región del sureste de Turquía.

10. Remite al artículo «Kars» de la Encyclopedie de l'Islam, 2. ${ }^{a}$ ed., vol. IV, pp. 696-699.
} 
Identificadas con cierta seguridad las cinco ciudades, hay que intentar calificar geopolíticamente esas regiones de implantación de los moriscos ${ }^{11}$.

La primera observación que se advierte en esas implantaciones es que al menos tres de ellas están en regiones deltaicas de gran capacidad productiva agrícola (Adana, Sis, Tarsus), en Cilicia, en zonas mediterráneas semejantes a las de las Ilanuias levantinas de España (Cataluña, Valencia, Murcia). Corresponde a la finalidad expresada en el documento: "...para que vivan cultivando la tierra...".

La segunda observación se refiere también a al menos tres de las cinco poblaciones citadas: están en zonas de importante control militar, de pasos estratégicos o fronterizos (Sis, Azaz, Kars). Su situación corresponde a las necesidades prioritarias de control político-administrativo de las vías de comunicación del inmenso Imperio Otomano.

Una tercera observación se refiere también al conjunto de las cinco ciudades alrededor de las cuales se instalarán los moriscos hispanos: son regiones que no son arabehablantes, aunque haya seguramente arabehablantes, especialmente en las cosmopolitas ciudades, y el árabe sea en esas regiones lengua oficial de la religión, junto con el turco, lengua de la administración. Se trata de regiones de lengua turca, armenia, kurda... Los moriscos, en su mayoría de lengua hispana, son perfectamente extranjeros en esas zonas. Esta situación cultural les hace particularmente dependientes de las autoridades turcas, lo cual facilita también su organización autónoma, bajo el control central otomano, con una asimilación en la región que sólo el tiempo realizará, lentamente. Los moriscos expulsados de España a principios del XVII son considerados por las autoridades otomanas, evidentemente, como musulmanes no-árabes, con discontinuidad lingüística y cultural con sus antepasados arabehablantes de Al-Ándalus.

Estas tres características (regiones agrícolas, regiones estratégicas, regiones "aljamiadas" de lengua no-árabe) se comprenden mejor comparando esas instalaciones de Anatolia con las del Mágreb árabe.

\section{INSTALACIÓN SOCIAL DE LOS MORISCOS: CAPITALES, ZONAS AGRÍCOLAS PERIURBANAS, GUARNICIONES DE FRONTERAS}

Ese documento, por ahora único, sobre implantaciones moriscas en Anatolia oriental confirma, en efecto, las principales características con las

11. Puede uno preguntarse si el orden en que aparecen las cinco ciudades en el documento (Adana, Sis, Azir o Azaz, Tarsus y Kars) es significativo. Está, evidentemente, la prioridad de Adana, primera en la lista y, sin duda, la ciudad más importante, políticamente. También está el hecho de que Kars, la última de las ciudades de la lista, esté en los límites orientales y septentrionales del Imperio Otomano, la más alejada de Estanbul, capital del Imperio Otomano y lugar desde donde el sultán Ahmed I expide este texto oficial o firmán. 
que intentamos sintetizar la forma de insersión de los moriscos hispanos en tierras magrebíes ${ }^{12}$.

Los moriscos, protegidos especialmente por los poderes políticos supremos de esas regiones (sultanato marroqui, califato otomano), se instalan prioritariamente en las ciudades que esos poderes controlan bien y directamente (Marrakech, Salé-Rabat, Tetuán, Tlemcén, Cherchel, Argel, Bugía/Bidjaia, Bona/Annaba, Bizerta, Túnez, Susa, Trípoli, Derna, Alejandría,...). Allí serán comerciantes - de mayor o menor categoría-, artesanos, docentes y funcionarios, y con propiedades agrícolas periurbanas (a menudo todo ello al mismo tiempo). También en esas ciudades portuarias ejercerán oficios relacionados con el mar: comercio, guerra de corso, armamento de naves... En una palabra, participarán en la importante vida cosmopolita del Mediterráneo del XVI-XVIII, con otros grupos islámicos y judíos, también de origen europeo u oriental, bajo control político de las autoridades respetadas de esas ciudades.

También bajo el control político de esas ciudades costeras, se instalarán en importantes y a veces muy extensas regiones agrícolas vecinas: huertas periurbanas o zonas fluviales de valles y deltas magrebies (valles de desembocadura del río Bu-Regreg y del Martín, en Marruecos; valle de la Mitidja, alrededor de Argel; valle del río Medjerda, en Tunisia; como los deltas del Seyhán y del Ceyhán, en Cilicia). Su carácter agrícola es periurbano, con comercio con las ciudades, de naturaleza totalmente diferente del semi-nomadismo rural de la población tradicional magrebí, donde rara vez se instalarán los moriscos, por sentirse extranjeros y desprotegidos.

Desde el punto de vista cultural y lingüístico, aunque las ciudades magrebíes siempre tuvieron por lengua común el árabe, en el XVI circulaban otras lenguas, tanto el beréber tradicional (en Argelia y Marruecos) como el turco (en las regencias otomanas de Argelia, Túnez y Trípoli) y otras lenguas portuarias mediterráneas. El poliglotismo cultural del Mágreb, en su zona costera, se daba también en aquellas regiones urbanizadas y de tránsito donde se instalaron los moriscos de Anatolia.

Finalmente, otra característica muy importante señala la implantación de los moriscos emigrantes de España en sus destierros magrebíes: su frecuente insersión en las estructuras militares de los países de acogida, navales o terrestres. Como extranjeros que son, aunque musulmanes, sirven a los soberanos en sus necesidades militares, especialmente en las expediciones de control de los espacios y de los puestos estratégicos.

No veo, en cambio, elemento significativo en el orden de las ciudades 2 (Sis), 3 (Azir o Azaz) y 4 (Tarsus).

12. Ver M. de EpAlzA, Los moriscos antes y después de la expulsión..., especialmente pp. 133-210. El análisis de las implantaciones en Tunisia y en los territorios de la actual Libia (Trípoli, Derna) confirman también esa presentación. 
Estas tres características, profusamente documentadas en los moriscos del Mágreb, también se ven confirmadas en el documento sobre los moriscos de Anatolia.

El carácter urbano y periurbano de estos establecimientos magrebíes se da en los territorios de Cilicia, alrededor de las ciudades de Adana, Sis y Tarsus, con sus llanuras fluviales. El carácter militar de vigilancia de pasos estratégicos (Kars, Azaz) recuerda la importancia militar de los establecimientos militares andalusíes en el Mágreb: los cuerpos de ejército andalusíes del gobierno de Argel del segundo cuarto del siglo XVI y los del sultán marroquí Al-Mansur Adh-Dháhabi, con el morisco Djaudar Bacha y la expedición a Tumbuctú; los puertos marroquíes de Salé-Rabat y Tetuán; la ciudad fronteriza de Tlemcén, con sus fabricantes andalusíes de armas, frontera del gobierno turco de Argel contra sus enemigos septentrionales (los españoles del enclave Orán-Mazalquivir) y occidentales (los sultanes marroquíes); atarazanas de Cherchel, en Argelia; nuevo puerto militar de Porto-Farina (GarEl-Melh), en Tunisia; actividades arquitecturales y navieras en toda la costa atlántica y mediterránea; etc. La misma personalidad militar del jefe de los moriscos de Anatolia recuerda a otras personalidades militares moriscas documentadas en el Mágreb, especialmente al marino Abd-Al-Gánim, autor del conocido manual de artillería, traducido al árabe por el también morisco Shihab-ad-din Al-Hadjari Bejarano.

\section{PRECISIONES SOBRE LA PERSONALIDAD DEL JEFE DE LOS ANDALUSÍES}

Temimi, en su estudio del firmán imperial otomano de 1613, afirma que "no hemos encontrado ninguna información sobre este personaje"13, cuyo nombre transcribe Alí Bin Muhámmad el Mutafárrika. Pero intenta sacar alguna información del documento mismo. Es lo que vamos a intentar nosotros también, profundizar un poco más.

El primer dato importante sobre ese personaje es que se le designa como "uno de ellos", es decir un morisco exiliado de España. Posiblemente se le denominaría Al-Andalusí, "originario de Al-Ándalus" (o simplemente Andalusí, sin el artículo árabe, en turco), como a tantos otros moriscos instalados en el mundo islámico, documentados -por ejemplo- en otros territorios del Imperio Otomano, como Tunicia ${ }^{14}$.

13. Ver L'expulsió..., p. 169, nota 30.

14. Ver en M. de EPALZA, «Moriscos y andalusies en Túnez en el siglo XVII», Al-Andalus, Madrid, 34, 1969, pp. 247-327, traducido al francés (sin los índices onomásticos) en M. de EPAlzA y R. PetiT (edits.), Receuil d'études..., pp. 150-186. 
El nombre personal (Alí) y el de filiación (Ibn Muhámmad) son absolutamente comunes en el Islam: Alí es el nombre del primo carnal de Mahoma, por parte paterna, su compañero de batallas y futuro yerno, esposo de su hija Fátima y padre de su única descendencia masculina: sus nietos Hasan y Husáin; Muhámmad es el nombre árabe correcto de Mahoma, que se pronunciaría seguramente Mohamed, como es normal en territorios turcohablantes y en el Mágreb. Es probable también que el nombre de filiación Bin Muhámmad, "Hijo de Muhámmad" (en árabe correcto Ibn Muhámmad) se pronunciara Ben-Muhámmad. Poco más puede sacarse del análisis de la onomástica personal del personaje ${ }^{15}$.

En cambio el nombre o título profesional del personaje contiene informaciones importantes: "el Mutafárrika", según Temimi, que prefiero leer simplemente "el mutafárriqeh", en el turco del documento ${ }^{16}$.

Temimi, basándose en un diccionario moderno de terminología histórica turca ${ }^{17}$, indica que el mutafárrika es un funcionario de alto rango, que tiene por tarea ser el intermediario y el interlocutor entre el Diwán (sede del poder) y los Emires de las provincias; como podría ser encargado por el Diwán de misiones especiales. Dozy ${ }^{18}$ recoge útiles precisiones sobre esta palabra árabe, en las acepciones que tomó al pasar a la lengua turca, como es el caso en nuestro El Mutafárrique. Aporta documentación de este nombre entre los cargos de navíos o de caballeros titulares de feudos. Más cercano, seguramente, a nuestro personaje serían las acepciones de diccionarios de turco: "Los Mutaferagas y los Chiaoux, pequeños oficiales empleados por el Pachá", "caballeros que acompañan al sultán en sus viajes y son encargados por él de ciertos encargos" o, sobre todo, el cargo subalterno de bâsh mutafárriqeh ("sub-mutafárriqeh"), que Dozy define como "sub-oficial que busca

15. En realidad, examinando la fotografía del texto turco y su transcripción (op. cit., pp. 169 y 170), yo no acierto a leer esos nombres, sino el título árabe "mu allim" ("maestro", con significado de artesano o de profesor), en su forma turca $m i$ allêm, precediendo el también nombre de oficio mutafárriqeh. Es posible que el prof. Temimi, con su experiencia de la documentación otomana, haya visto mejor que yo en el documento la abreviatura de "Alí lbn Muhammad".

16. La diferencia entre los dos nombres es sencilla. Por una parte el original $\mathfrak{q}$ de mutafárrigeh ha sido transcrito por $k$ por Temimi en la traducción francesa -no en la árabe- para facilitar su pronunciación en esa lengua. En cambio, la desinencia adjetival turca -eh suele transcribirse en árabe con una ilógica terminación femenina -a, con tấ marbîta, para evitar el equívoco con la hấ final del pronombre afijo de $3 .^{a}$ persona singular (así se prefiere la lógica gramatical, aunque sea a costa del uso del género femenino para un cargo masculino). En eso consiste la diferencia entre las dos transcripciones. Para un nombre histórico, en transcripción castellana, es mejor respetar el texto turco en una transcripción lo más fiel posible al original del siglo XVII: EI Mutafárriqeh (o en escritura más hispanizada El Mutafárrique).

17. Ver op. cit., p. 169 , nota 31 .

18. Ver R. DozY, Suppléments aux dictionnaires arabes, Leyden, 1881; Beyrut, 1968, t. 11, p. 260. 
los alojamientos y distribuye el pan a los soldados". La etimología árabe de la palabra (de la raíz trilítera $f-r-q$, con sentido general de "distribuir") explica ese papel de "intendencia" militar, en el séquito de las expediciones del sultán turco-otomano, para el alojamiento y alimentación de los soldados.

Es pues en este ambiente social de inserción militar del morisco y de su relativa proximidad al poder central otomano, en el ejército del sultán, donde hay que situar el origen del nombramiento de Alí Ibn-Muhámmad El Mutafárrique como "sanchaq-bey" de los moriscos de Anatolia.

El texto turco dice sandjâq-bayk, transcripción habitual y defectiva de dos palabras muy específicas de la administración militar turca. El "sanchaq" (o "sandjak", por adaptación del francés) es el nombre de una circunscripción o provincia militar" 19 ."Bey" (en turco "señor") es título de aplicación variada, que Temimi traduce, seguramente mediante el árabe, por "Emir Sanjak". El otomanista tunecino opina que es un cargo importante, cuyo nombramiento implica un firmán imperial, y que supone un número importante de súbditos a sus órdenes.

Se puede plantear, también, la naturaleza específica de ese cargo, a falta de documentación más precisa sobre la figura del "sanchaq-bey" en la administración turco-otomana de principios del siglo XVII. Parece que tiene unas características militares, como el de su titular el "intendente" o mutafárrique, aunque el documento sólo especifique que el Sultán le encarga "de velar por sus asuntos [de los moriscos] y por su seguridad". También puede dudarse que tenga jurisdicción sobre un territorio, como lo indicaría la palabra "sanchaq": sería más bien una jurisdicción sobre el grupo, la "taifa", según una fórmula de gobierno muy propia del Imperio Otomano. En el documento se menciona el paralelismo con Tunicia, donde los andalusies tienen un shayj, probablemente Luis Zapata, por esas fechas, antes de que asuma el cargo el también comerciante Mustafá de Cárdenas ${ }^{20}$. Es muy probable que la figura de "jefe de la comunidad morisca" sea semejante, en Anatolia y en Túnez, para la administración otomana, aunque el titular de los de Anatolia sea de origen militar y el de los de Tunicia sea de origen comerciante. Pero otros factores de diferenciación parecen evidentes: el número sin duda mayor de

19. "Estandarte, regencia [en la administración otomana]", según F. CorRIENTE, Diccionario árabe-español, 2. ed., Madrid, 1986, p. 376, recogiendo así dos elementos fundamentales del término: su sentido de "cuerpo de ejército" (estandarte) y el de "territorio o circunscripción militar" (regencia). Palabra de origen no-árabe, en árabe se escribe sandjaq o sindjaq, pero nuestro texto en turco escribe sanchâq, que habría que pronunciar probablemente, en español, "sanchek". En su reciente y excelente diccionario de Iengua árabe moderna, el profesor Julio Cortés atribuye a la palabra árabe sandjaq un origen turco y la traduce por "bandera; regencia, subdivisión administrativa otomana de una provincia" (Diccionario de árabe culto moderno. Árabe-español, Madrid, 1996, p. 537). Para el uso de la palabra bey en árabe moderno -no, evidentemente, en el turco o turquificado del siglo XVII-, id., pp. 61 y 95).

20. Ver, sobre los personajes y sus cargos, M. de EPALZA, «Moriscos y andalusíes...», pp. 284-293. 
inmigrantes en Túnez o su mayor concentración alrededor de la capital, y no la dispersión de las cinco ciudades anatólicas citadas.

El documento de 1613 tiene por finalidad principal mostrar el apoyo de la autoridad suprema otomana a la insersión de los moriscos, tanto en Anatolia como en Tunicia ${ }^{21}$. Por ello, el documento de 1613 requiere una explicación global de la política imperial otomana en favor de los moriscos.

\section{POLÍTICAS MUSULMANAS DE ACOGIDA: DE PODERES CENTRALES (ANDALUSÍES COMO GRUPOS INTEGRADOS) Y DE SOCIEDADES LOCALES (ANDALUSÍES ASIMILADOS)}

No se va a estudiar - ni siquiera a presentar- la política general otomana en el proceso de integración de los moriscos expulsados de España ${ }^{22}$. Es tema que ha tenido su mejor investigador -y apologeta- precisamente en el profesor Abdeljelil Temimi, especialmente en sus dos libros, colección de monografías: Le Gouvernement ottoman et le problème morisque ${ }^{23}$ y Études d'histoire morisque ${ }^{24}$. Pero sí conviene recordar, para comprender mejor el alcance del texto de 1613, dos elementos importantes que explican muchos factores de la política otomana con los moriscos: el origen y evolución del Imperio Otomano, hasta la época de la expulsión de los moriscos, y su forma de gobierno por "taifas" étnico-religiosas.

Los turcos otomanos son una de las muchas ramas de los pueblos turcos, de origen centroasiático, instalados en Iraq y en el Oriente Medio islámico y formando paulatinamente la vanguardia de la frontera islámica frente a Bizancio, en Anatolia. A principios del siglo XV, los turcos otomanos fueron aniquilados por los ejércitos de Tamerlán, como todos los demás poderes islámicos de Anatolia. Pero se recuperan rápidamente, encabezan todas las fuerzas islámicas contra los cristianos bizantinos $y$, medio siglo después (1453), conquistan Constantinopla/Bizancio, que transformarán en su capital, con el nombre de Istanbul (Estanbul, en español; Istana, en árabe). Se ex-

21. Donde hay dificultades, como lo muestra también otro firmán otomano, de 1615, estudiado por A. TEMINI, «Évolution de l'attitude des autorités de la Régence de Tunis face à l'acceuil des Morisques, à la lumière d'un nouveau firman du sultan ottoman", Actes du Ve Symposium International d'Études morisques, Le Ve Centenaire de la chute de Grenade 1492-1992, Zaghouan, 1993, t. II, pp. 711-722, y Études d'Histoire Morisque, pp. 25-39.

22. Ver estudio sintético de este problema (utilizado y mencionado por A. Temimi, Études d'Histoire..., p. 29, nota 19) de M. de EPALZA, «Les Ottomans et l'insertion au Maghreb des Andalous expulsés d'Espagne au XVIle siècle», Revue d'Histoire Maghrébine, 31-32, 1984, pp. 165-173.

23. Zaghouan, 1989, 185 págs.

24. Zaghouan, 1993, 168 págs. 
tienden por los Balcanes hacia Europa central (Grecia, Tracia, Macedonia, Albania, el valle del Danubio...), ocupan casi todo el Oriente Medio árabe, a principios del siglo XVI (Siria y Palestina, Egipto, Iraq, Arabia...) y se alían con poderes locales en el Norte de África (Argel, Tremecén...) para expulsar a los españoles y malteses de la costa magrebí a lo largo del siglo XVI (Trípoli, Gelves/Djerba, África/Mahdia, Hamamet, La Goleta y Túnez -en 1573-, Bizerta, Tabarca, Bona/Annaba, Bujía/Bidjaia, Peñón de Argel, Tenés, Honéin...), dejando a los españoles sólo el enclave de Orán-Mazalquivir y llegando a ocupar gran parte de Menorca, a finales del XVI ${ }^{25}$.

Esta amplísima expansión geográfica supuso un control político muy eficaz de los muy diversos pueblos que componían el Imperio Otomano. Ese control se hacía con una administración centralizada, de fuerte componente militar (control por personal militar de la administración central y de sus ramificaciones provinciales, control militar de las vías de comunicación terrestres y de los puertos marítimos). Pero también instalaron los turcos otomanos un sistema de poderes locales, con jefes de comunidades étnicoreligiosas, responsables políticos y fiscales ante la autoridad central otomana. Este sistema, particularmente complejo en la región siro-palestina o Bilad-ax-Xam, estaba basado en las "comunidades religiosas" (milleh o millet, cristianas, judías, drusas...) o, con un término más general, en las "taifas" (taifeh, plural tawaif) o "comunidades étnico-religiosas".

En este sistema quisieron los poderes otomanos integrar a los moriscos expulsados de España, en una primera etapa, preservando su identidad cultural y sus autoridades autónomas (shaij, sanchaq-bey...), como se ve en el documento de 1613. De ahí el uso tan frecuente de la palabra taifeh en ese texto, como se ha visto, para designar a la comunidad de los moriscos. Forma parte de la política administrativa turca, de mantener divididos y controlados a los pueblos de los inmensos territorios que gobernaban.

Esta administración por taifas no tenía tradición en el Mágreb ni convenía muchas veces a los poderes locales. De ahí la resistencia de algunas autoridades, como lo demuestran éste y otros documentos, en el caso de Tunicia $^{26}$. Los moriscos se acogieron, en un primer momento, a esa estructura autónoma, como lo habían hecho en Marruecos, en Salé-Rabat y en Tetuán y

25. Ver síntesis de esta historia turco-española en M. de EPALZA y J.B. VILAR, Planos y mapas hispánicos de Argelia. Siglos XVI-XVII, Madrid, 1988, y J.B. VILAR, Mapas, planos y fortificaciones hispánicos de Túnez (s. XVI-XIX), Madrid, 1991.

26. Ver M. de EPALZA, «Les Ottomans...», y A. TEMIMI, «Évolution de l'attitude des autorités de la Régence de Tunis, face à l'acceuil des Morisques, à la lumière d'un nouveau firman du sultan ottoman» [documento de 1615, complementario del de 1613, pero sin mención de los moriscos de Anatolia], Études d'Histoire..., pp. 25-39 [en francés], pp. 25-42 [en árabe], y Actes du Ve Sumposium International d'Études morisques. Le Ve Centenaire de la Chute de Grenade 1492 - 1992, Zaghouan, 1993, II, pp. 711-722 [en francés], pp. 53-66 [en árabe]. 
su región, con respecto a la autoridad de los soberanos de Marrakech, con autonomía política casi completa ${ }^{27}$. En Tunicia, la figura del "shaij de los andalusíes" perdura, con mayor o menor fuerza, hasta el último tercio del siglo XVII, manteniendo la coherencia cultural y fiscal de la comunidad de los moriscos expulsados de España, hasta en la formación de cuerpos específicos de ejército, que colaboran con las autoridades locales frente a invasiones argelinas de la Regencia de Túnez $z^{28}$.

La tensión entre poder central otomano, partidario de la integración diferenciada de los moriscos en la sociedad islámica -al menos en los primeros años después del exilio-, y los poderes locales magrebíes, partidarios de la asimilación, es manifiesta en este documento de los primeros años después del éxodo morisco. Más adelante, la realidad asimilacionista acabaría imponiéndose, desde el punto de vista administrativo, pero también cultural, ya que los moriscos perderían totalmente el uso de la lengua española a mediados del siglo XVIII y sólo conservarían algunos elementos de ese origen: la conciencia de su origen andalusí, algunos apellidos de origen peninsular y pocas palabras hispanas (en el léxico artesanal, agrícola y doméstico) ${ }^{29}$.

El documento de 1613 y el asentamiento de moriscos en Anatolia son un buen ejemplo de las tensiones que produjo, a nivel de la sociedad islámica mediterránea, la expulsión de los moriscos de la sociedad hispánica, entre 1609 y 1614.

\section{RESUMEN}

En este documento de los archivos turcos, de 1613, se mencionan cinco localidades de Anatolia donde se instalaron moriscos, después de la general expulsión de España de 1609-10. Identificadas con más precisión esas cinco poblaciones (ver mapa), se estudia su situación geopolítica, comparándola con otros asentamientos del Mágreb. También se analiza el nombre y cargo político de su jefe, Alí Ibn Muhámmad El Mutafárrique.

\footnotetext{
ABSTRACT

In this document (1613) of the Turkish files five localities of Anatolia, where the Moorish settled, after the general expulsion from Spain in 1609-10,

27. Ver supra, nota 2, y G. Gozalbes Busio, Los moriscos en Marruecos, Granada, 1992.

28. Ver supra, nota 18.

29. Ver M. de EPALZA, «La vie intellectuelle en espagnol des morisques au Maghreb (XVIIe siècle)», Revue d'Tistoire Maghrébine, 17/59-60, 1990, pp. 73-78, y «El català en el Màgreb àrab. Els moriscos expulsats», II Congrés Internacional de la Llengua Catalana, València, 1989, vol. 8, pp. 385-388.
} 
are mentioned. Identified with more precision (see map), their geopolitical situation is studied in comparison with other settlements in the Magreb. The name and political office of their chief, Alí Ibn Muhámmad El Mutafárrique, is also analyzed.

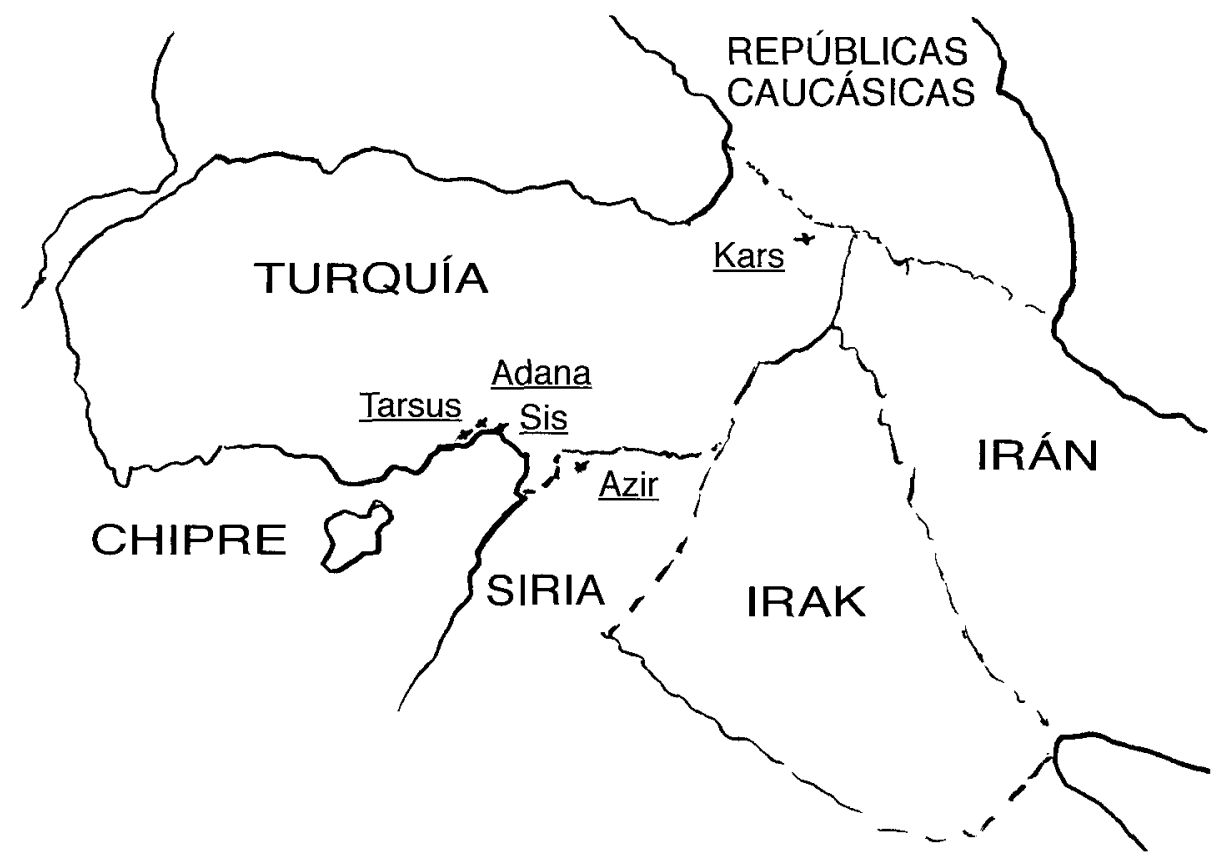

Mapa esquemático de los estados modernos, con la situación de las cinco poblaciones mencionadas de asentamiento morisco 